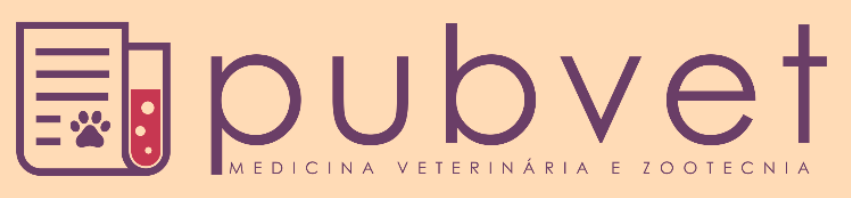

https://doi.org/10.31533/pubvet.v15n07a869.1-8

\title{
Avaliação do nível de conhecimento da população sobre leite cru, UHT e pasteurizado em 18 estados brasileiros
}

\author{
Amanda de Oliveira Veloso ${ }^{1 *} \bullet \mathbb{D}$, Mariane Vignoli Pereira ${ }^{1} \bullet \mathbb{D}$, Marcus Vinicius Cotrim \\ Pimenta $^{1} \bullet \mathbb{D}$, Yasmim Rocha de Castro ${ }^{1} \mathbb{D}$, Paola Rodrigues Brígida ${ }^{1} \odot \mathbb{D}$, Renato Leite Silveira ${ }^{1}$ \\ (D), Fabiana Batalha Knackfuss ${ }^{2}$ C
}

${ }^{I}$ Discente do Curso de Medicina Veterinária da Universidade do Grande Rio-UNIGRANRIO. Duque de Caxias - RJ, Brasil.

${ }^{2}$ Professora Adjunta do Curso de Medicina Veterinária da Universidade do Grande Rio - UNIGRANRIO, Duque de Caxias - RJ, Brasil.

*Autor para correspondência, E-mail: amanda.o.veloso@gmail.com

\begin{abstract}
Resumo. O presente estudo teve como objetivo avaliar do consumo de leite cru, UHT/UAT (Ultra-alta temperatura) e pasteurizado através de questionário realizado pela plataforma digital "Google forms", utilizada para a avaliar as preferências e regularidade de consumo dos entrevistados em relação a esses lácteos, bem como o risco de contaminação por microrganismos e os valores nutricionais que cada variedade de leite teria segundo eles. Foram obtidos trezentos e setenta e quatro questionários respondidos provenientes de dezoito estados brasileiros, e realizou-se a tabulação de seus resultados para uma melhor visualização dos dados, desta forma pôde-se compreender os motivos que levaram as pessoas a escolherem o tipo de leite consumido. Durante a pesquisa foi observado que grande parte dos entrevistados informou acreditar que o leite cru seria mais saudável, já que segundo eles o mesmo possui mais nutrientes, menor contaminação bacteriana ou não apresenta conservantes, no entanto, apenas uma pequena parcela dos entrevistados respondeu consumir leite cru. Em contrapartida, a maioria dos entrevistados afirmou consumir leite UHT ou pasteurizado, e destes pouco mais da metade relataram que esses lácteos seriam melhores que o leite cru. Ao fim desta pesquisa observou-se que a população brasileira ingere grande quantidade de leite pasteurizado ou UHT, movimentando boa parte da indústria brasileira e tendo perspectiva de crescimento do consumo e aumento nesse segmento do mercado, ao passo que ainda há preconceitos referentes a esses lácteos por conta de fraudes notificadas em jornais.
\end{abstract}

Palavras-chave: Leite cru, leite UHT, microrganismos, pasteurização, valor nutricional

\section{Evaluation of the population's level of knowledge about raw, UHT and pasteurized milk in 18 Brazilian states}

\footnotetext{
Abstract. The present study aimed to evaluate the consumption of raw, UHT/UAT (Ultrahigh temperature) and pasteurized milk through a questionnaire carried out by the digital platform "Google forms", used to evaluate the preferences and regularity of consumption of the interviewees in relation to these dairy products were evaluated, as well as the risk of contamination by microorganisms and the nutritional values that each variety of milk would have according to them. Three hundred and seventy-four questionnaires were obtained, answered from eighteen Brazilian states, and their results were tabulated for a better visualization of the data, in this way it was possible to understand the reasons that led people to choose the type of milk consumed. During the survey it was observed that a large part of the interviewees reported believing that raw milk would be healthier, since according to them it has more nutrients, less bacterial contamination or does not contain preservatives, however, only a small portion of the respondents responded to consuming
} 
milk crude. In contrast, the majority of respondents said they consume UHT or pasteurized milk, and of these just over half reported that these dairy products would be better than raw milk. At the end of this research it was observed that the Brazilian population ingests a large amount of pasteurized or UHT milk, moving a good part of the Brazilian industry and having a perspective of growth in consumption and an increase in this segment of the market, while there are still prejudices regarding these dairy products. due to fraud reported in newspapers.

Keywords: Raw milk, UHT milk, micro-organisms, pasteurization, quality, nutritional value

\section{Evaluación del nivel de conocimiento de la población sobre leche cruda, UHT y pasteurizada en 18 estados brasileños}

Resumen. El presente estudio tuvo como objetivo evaluar el consumo de leche cruda, UHT/UAT (Temperatura ultra alta) y pasteurizada a través de un cuestionario realizado por la plataforma digital "formularios de Google", utilizado para evaluar las preferencias y regularidad de consumo de los entrevistados en relación con estos productos lácteos, así como el riesgo de contaminación por microorganismos y los valores nutricionales que tendría cada variedad de leche según ellos. Se obtuvieron trescientos setenta y cuatro cuestionarios, respondidos de dieciocho estados brasileños, y sus resultados fueron tabulados para una mejor visualización de los datos, de esta manera se pudo comprender las razones que llevaron a las personas a elegir el tipo de leche consumida. Durante la encuesta se observó que gran parte de los entrevistados refirió creer que la leche cruda sería más saludable, ya que según ellos tiene más nutrientes, menos contaminación bacteriana o no contiene conservantes, sin embargo, solo una pequeña porción de los encuestados respondió al consumo de leche cruda. Por el contrario, la mayoría de los encuestados dijeron que consumen leche UHT o pasteurizada, y de ellos, poco más de la mitad informó que estos productos lácteos serían mejores que la leche cruda. Al final de esta investigación, se observó que la población brasileña ingiere una gran cantidad de leche pasteurizada o UHT, moviendo buena parte de la industria brasileña y con una perspectiva de crecimiento en el consumo y un aumento en este segmento del mercado, si bien aún existen prejuicios con respecto a estos productos lácteos debido al fraude reportado en los periódicos.

Palabras clave: Leche cruda, leche UHT, microorganismos, pasteurización, valor nutricional

\section{Introdução}

O Brasil tem o leite como o segundo segmento mais importante da indústria de alimentos, e dentro dos produtos lácteos mais consumidos se tem o leite longa vida ou UHT (Siqueira, 2019). O mesmo é considerado o quarto maior produtor mundial de leite, e está atrás apenas da Índia, dos Estados Unidos e do Paquistão, além de apresentar grande capacidade de crescimento e aumento da competitividade na

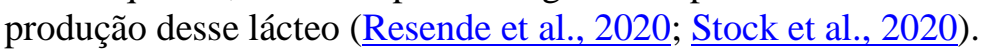

O leite é uma matéria prima de grande importância econômica, sendo fonte de renda e sobrevivência para boa parte da população do mundo, além de ser um alimento de alto valor nutricional com presença de proteínas, glicídios, sais minerais e vitaminas. Devido à sua fonte nutritiva e também à sua versatilidade de consumo, diariamente bilhões de pessoas ingerem leite em todo o mundo em suas mais diversas formas, desde o leite cru, até derivados doces e salgados como manteigas, queijos e outras formas lácteas (Siqueira, 2019; Vidal \& Saran Netto, 2018).

A riqueza do leite permite a sua contaminação por diversas bactérias, por isso, é de grande importância obter-se informações sobre as suas formas de tratamento, conservação e o consumo do mesmo. O leite cru, por não passar por processamento térmico pode servir de proliferação para diversas bactérias, como: Lactococcus, Streptococcus, Leuconostoc, Lactobacillus, Flavobacterium spp., Acinetobacter spp., Clostridium botulinum, Bacillus stearothermophilus, Enterococcus e Listeria monocytogens; além de algumas bactérias de origem fecal (Ordoñez, 2005). 
A pasteurização do leite é um tratamento térmico aplicado ao mesmo com o intuito de evitar riscos à saúde pública causados por microrganismos. A mesma pode ser feita de forma lenta ou rápida, e têmse a rápida como a forma mais utilizada, a qual baseia-se no aquecimento indireto do leite entre $72^{\circ} \mathrm{Ce}$ $75^{\circ} \mathrm{C}$ por quinze a vinte segundos, enquanto, para a produção do leite UHT (Ultra Alta Temperatura) aplica-se um tratamento térmico a uma temperatura entre $130^{\circ} \mathrm{C}$ e $150^{\circ} \mathrm{C}$ por dois a quatro segundos por um processo de fluxo contínuo, imediatamente resfria-se esse lácteo a uma temperatura inferior a $32^{\circ} \mathrm{C}$, e envasa-se o mesmo sob condições assépticas em embalagens esterilizadas e hermeticamente fechadas (BRASIL, 2017).

Este estudo teve como objetivo avaliar o consumo de leite cru, UHT e pasteurizado no Brasil, bem como verificar o conhecimento do brasileiro em relação aos perigos possíveis presentes no leite cru.

\section{Material e métodos}

Foi realizada uma pesquisa qualitativa no mês de novembro de 2020 por meio de um questionário com 16 perguntas por meio da plataforma "Google forms" e enviado através de um link nas redes sociais WhatsApp, Facebook, Twitter, Instagram e Telegram.

Obteve-se um total de 374 questionários respondidos nos estados brasileiros, sendo eles: Rio de Janeiro, São Paulo, Pará, Distrito Federal, Minas Gerais, Paraná, Espírito Santo, Goiás, Rondônia, Rio Grande do Sul, Sergipe, Pernambuco, Ceará, Bahia, Paraíba, Santa Catarina, Amazonas e Maranhão,

Após a obtenção das respostas os dados foram compilados em planilha Excel para posterior estimativa das frequências relativas de cada resposta, assim como elaboração de gráficos de setores e histogramas.

\section{Resultados e discussão}

Em relação ao gênero (Figura 1), a maioria foram mulheres (65\%), esses dados podem ser justificados por Greenberg et al. (2018) que relataram um estudo feito na universidade de Cambridge na Inglaterra, o qual diz que mulheres possuem mais empatia que homens, esses dados podem explicar o maior interesse do gênero feminino em responder questionários, já que estariam contribuindo para uma pesquisa importante; $34 \%$ foram homens e $1 \%$ foram não-binários. Em relação a idade (Figura 2), 35\% informaram ter entre 18 a 25 anos, sendo a faixa etária predominante; $18,8 \%$ menores de 18 anos; $20 \%$ pessoas entre 26 a 35 anos; $17,4 \%$ pessoas entre 36 a 49 anos; $16 \%$ entre 50 a 60 anos; $4 \%$ foram pessoas com mais de 60 anos, pois segundo Lechakoski \& Wildauer (2013), relatou-se que pessoas com essa faixa etária são os que menos utilizam a internet.

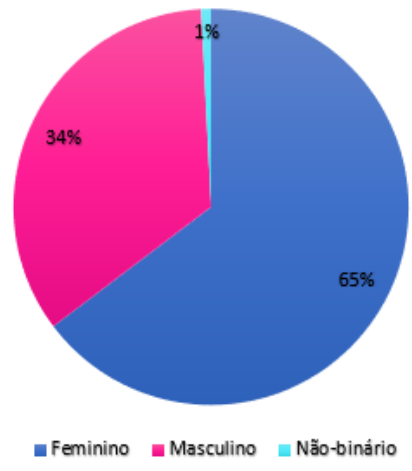

Figura 1. Percentual de respostas dos entrevistados referente ao gênero que se identificam

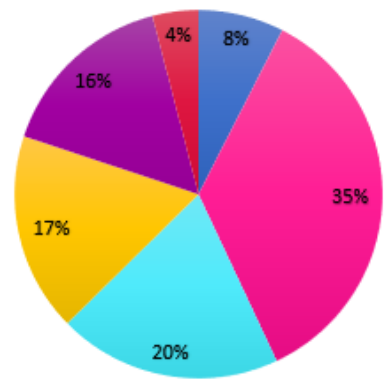

- Menor de 18 anos $=18$ a 25 anos $=26$ a 35 anos

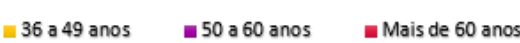

Figura 2. Percentual de respostas referente à faixa etária dos entrevistados

Sobre o grau de escolaridade (Figura 3), 27\% responderam possuir ensino médio completo; $26 \%$ informaram ter ensino superior incompleto, sendo grande parcela entrevistados, sugerindo que esse público teria maior chance de se interessar em responder pesquisas universitárias, já que se trata de estudantes de graduação. Referente aos outros entrevistados, $18 \%$ informaram possuir o ensino superior completo; $18 \%$ afirmaram ter pós-graduação; $7 \%$ relataram possuir ensino médio incompleto, enquanto 
somou-se $4 \%$ dos entrevistados que responderam possuir ensino fundamental completo, incompleto ou não possuir escolaridade.

Em relação a profisssão ou área de estudo (Figura 4), 21\% informaram ser da área da saúde, sendo que por conta da presente pesquisa se encontrar nessa área, sugere-se que houve maior interesse desses em responder do que os entrevistados de outras áreas. Referente aos outros dados, $19 \%$ afirmaram não possuir formação ou não ser estudantes de graduação; $13 \%$ declararam ser da área de educação; $12 \%$ mencionaram ser estudantes de ensino fundamental ou médio; $10 \%$ responderam ser da área de administração, economia e negócios.
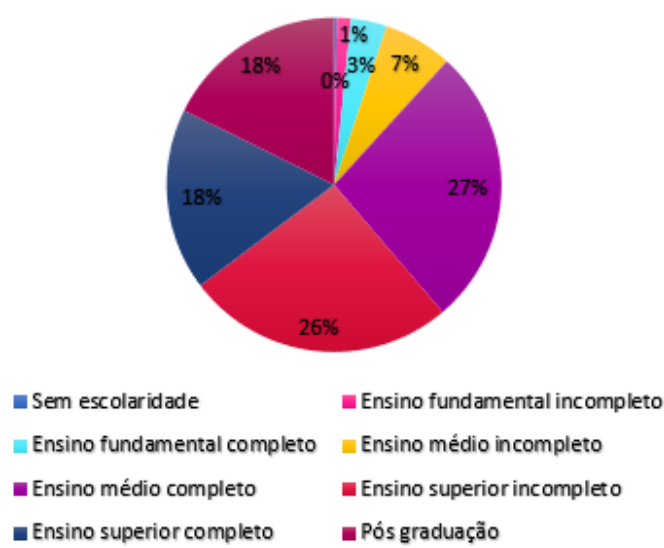

Figura 3. Percentual do grau de escolaridade dos entrevistados.

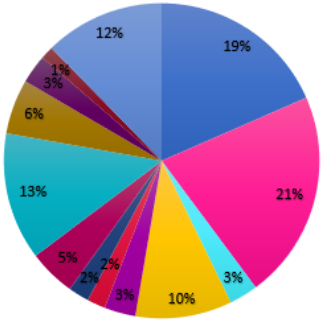

- Sem formação/área de estudo

- Ciências agrárias

- Ciências sociais

- Design e arte

- Educação

- Informação e tecnologia

- Estudante de ensino fundamental ou médio

Figura 4. Percentual de respostas referentes à área de estudo ou de formação dos entrevistados.

Quanto ao estado no qual os entrevistados residem (Figura 5), a maioria informou residir no estado do Rio de Janeiro (70\%), dado este podendo estar relacionado com o fato do grupo da presente pesquisa habitar o mesmo estado; em São Paulo foram 10\%, no Paraná foram 5\% e em Minas Gerais foram 3\%. No que se refere aos outros estados, não foram obtidos dados relevantes o suficiente para serem relatados, tendo-se uma soma de $12 \%$.

Referente ao consumo de leite cru (Figura 6), 70\% dos entrevistados informaram não consumir o mesmo, enquanto $21 \%$ informaram que sim, sendo a menor porcentagem referente aos que não bebem leite em geral (9\%). Em concordância com Amancio (2015), menor parte dos brasileiros ainda consome leite cru.

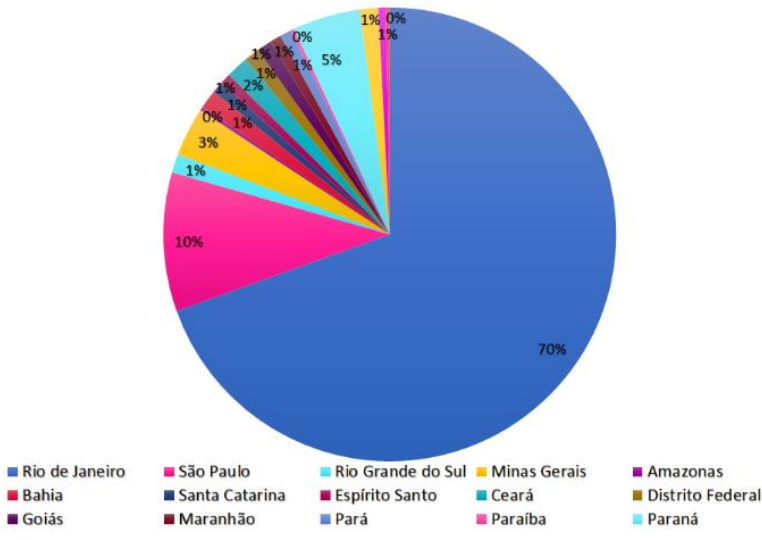

Figura 5. Percentual dos estados em que os entrevistados da presente pesquisa residem

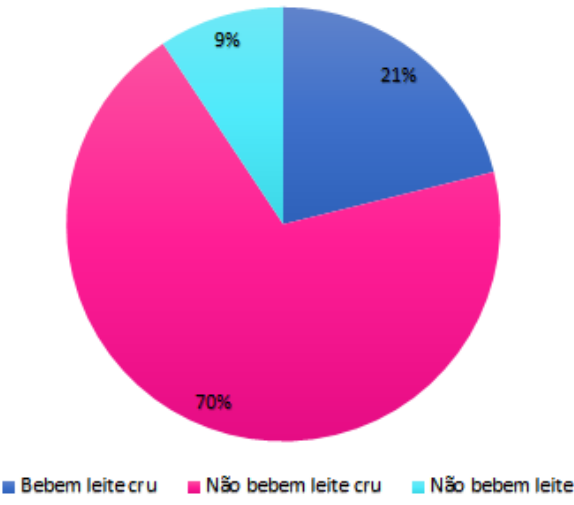

Figura 6. Percentual dos entrevistados que consomem ou não o leite cru, e os que não consomem qualquer leite

Dos entrevistados que consomem leite cru, $90 \%$ dos dados obtidos tiveram maior relevância, sendo $59 \%$ os que raramente bebem esse leite; $18 \%$ o ingerem 1 a 2 vezes por dia; e $13 \%$ o consomem 1 a 2 vezes por semana (Figura 7). Dessas pessoas que consomem o leite cru, $77 \%$ responderam que o fervem antes de ingeri-lo, dado este em conformidade com Longhi et al. (2010), a qual relatou que a maioria 
dos entrevistados consumidores de leite cru também o ferviam; $12 \%$ responderam que não fervem o leite; e 10\% informaram que às vezes o fazem (Figura 8).

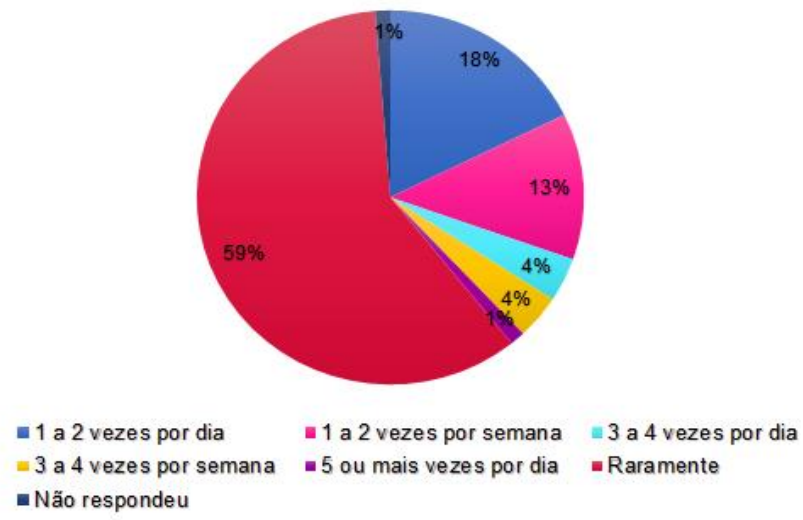

Figura 8. Percentual da frequência de consumo de leite cru referente aos entrevistados que ingerem o mesmo.

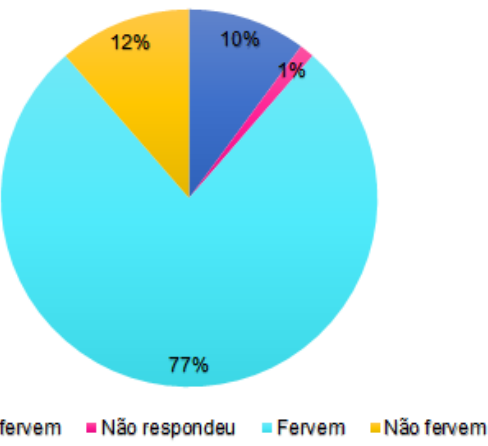

Figura 7. Dados percentuais referentes aos entrevistados consumidores de leite cru obtidos através da pergunta feita se os mesmos o fervem antes de ingeri-lo.

Na presente pesquisa, dos 374 entrevistados, $54 \%$ informaram acreditar que se o leite apenas fosse fervido em casa, o mesmo estaria livre de bactérias (Figura 9), discordando de Abreu \& Moési (2017), as quais sinalizaram que a fervura doméstica do leite cru tem a capacidade de apenas eliminar formas vegetativas de microrganismos, não tendo eficácia contra formas esporuladas altamente resistentes ao calor. Outra informação obtida foi que $46 \%$ acreditaram que o leite cru após fervido não estaria livre de bactérias.

De acordo com o questionamento se os entrevistados acreditavam que o leite cru seria mais saudável que os leites UHT e pasteurizado (Figura 10), 68\% acreditaram que sim, e $32 \%$ informaram que não. Sendo a maioria discordante com Ordoñez (2005), o qual diz que no interior do úbere da vaca, mesmo que esteja saudável, haverá bactérias frequentes que contaminam o leite no momento da ordenha, sendo elas principalmente micrococos, bactérias corineformes, e estreptococos, ou seja, o leite cru terá presença de bactérias, não sendo saudável para o consumo.

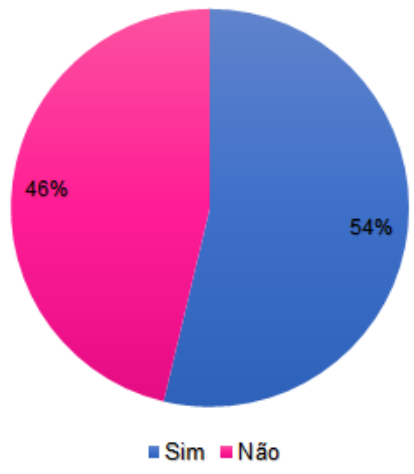

Figura 9. Percentual referente à pergunta elaborada aos entrevistados se os mesmos acreditam que a fervura doméstica do leite cru eliminaria as bactérias presentes no mesmo.

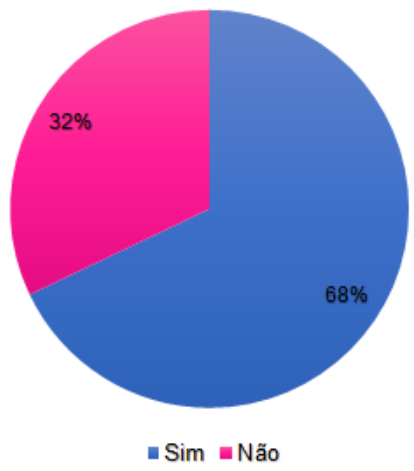

Figura 10. Percentual referente à pergunta feita aos entrevistados se os mesmos acreditam que o leite cru seria mais saudável que os tipos de leite UHT ou pasteurizado.

Das $68 \%$ pessoas que acreditam no leite cru ser mais saudável, $43 \%$ justificaram que o motivo seria pelo mesmo não apresentar conservantes comparado aos leites pasteurizado e UHT (Figura 11), da mesma forma que $37 \%$ das pessoas acreditavam que diferente dos leites UHT e pasteurizado, o leite cru não teria componentes químicos, discordando com a literatura referente ao artigo 251 , seção 2 do RIISPOA, BRASIL (2017), o qual informa que é proibida a utilização de substâncias químicas na conservação do leite.

A menor parte dos entrevistados (9\%) respondeu que ao ingerirem o leite cru, os mesmos absorveriam mais nutrientes, o que não acontece, já que segundo Sordi et al. (2015) essas pessoas 
poderiam ter diarreia pela presença de bactérias lácticas e/ou bactérias patogênicas, que fariam grande parte desses nutrientes absorvidos serem eliminados pelas fezes.

Dos entrevistados, $11 \%$ não souberam responder o motivo de acreditarem que o leite cru seria mais saudável.

Foram obtidas $83 \%$ de respostas alegando que essas pessoas consomem leite UHT ou pasteurizado, sendo $10 \%$ das pessoas informando que não ingerem qualquer leite, e apenas $7 \%$ dos entrevistados não serem consumidores desses tipos de leite (Figura 12). As respostas referentes àqueles que consomem leite UHT ou pasteurizado se assemelham às informações obtidas por Siqueira (2019), sendo 55\% os consumidores de leite UHT e 35\% os consumidores de leite pasteurizado, obtendo-se um total de $90 \%$ de consumidores desses leites, desta forma, indica-se que os casos de patologias adquiridas pela ingesta de leite cru possam ter diminuído.

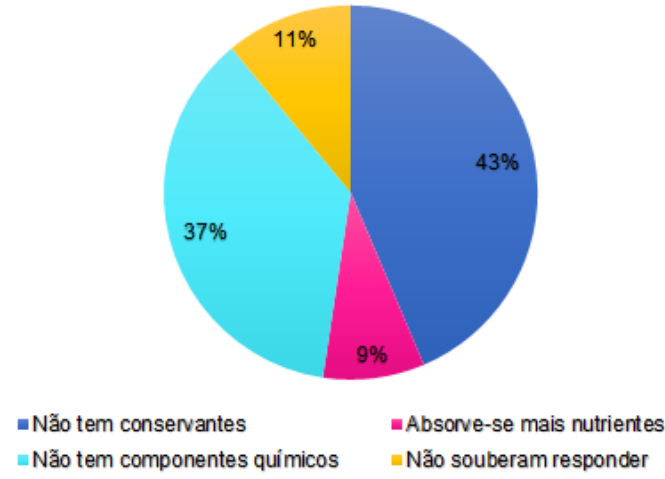

Figura 11. Percentual de respostas dadas pelos entrevistados referentes ao motivo dos mesmos acreditarem que o leite cru seria mais saudável que o UHT ou pasteurizado.

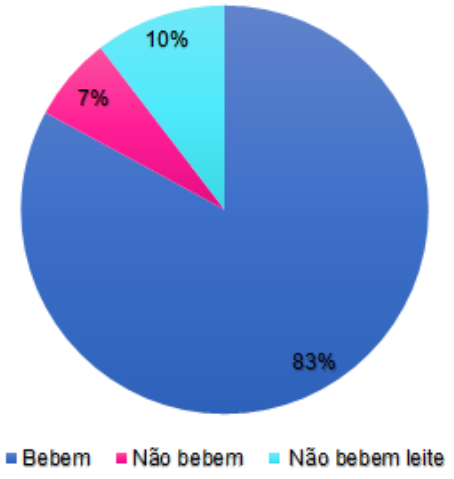

Figura 12. Percentual de respostas dos entrevistados sobre a pergunta se os mesmos consomem leite UHT ou pasteurizado.

A partir das respostas dos entrevistados que consomem leite UHT ou pasteurizado, obteve-se respostas relacionadas à tal consumo, sendo $39 \%$ os que citaram consumir os mesmos 1 a 2 vezes por dia, dados esses que segundo Amancio (2015) são importantes, pois recomenda-se o consumo de lácteos três vezes ao dia para que sejam atingidos os níveis de cálcio e proteínas diários recomendados. No que se refere ao restante dos entrevistados, $28 \%$ foram os que afirmaram raramente consumir esses lácteos; $16 \%$ os que informaram consumir 1 a 2 vezes por semana; $9 \%$ os que responderam consumilos 3 a 4 vezes por semana; e 5\% os que relataram ingerir esses lácteos 3 a 4 vezes por dia (Figura 13).

De acordo com a maioria dos entrevistados (70\%), os leites UHT ou pasteurizado não seriam melhores que o leite cru, enquanto 30\% acreditaram que sim (Figura 14). Dados estes preocupantes já que diferente da maioria dos entrevistados. Ordoñez (2005) informa que o leite pasteurizado não possui microrganismos patogênicos não-esporulados, além de reduzir grande parte da microbiota banal, e mantém suas características físico-químicas, nutritivas e sensoriais. O mesmo ainda informa que o leite UHT não possui microrganismos (esporulados ou não), sendo um produto micro biologicamente estável, podendo ser armazenado em temperatura ambiente por bastante tempo. Por esses motivos, esses tipos de leite têm qualidades melhores que o leite cru, algo que boa parte dos entrevistados não perceberam.

Dentre os 30\% dos entrevistados que concordaram que o leite UHT ou pasteurizado sejam melhores que o leite cru, $62 \%$ informaram esses serem mais seguros por não possuírem bactérias prejudiciais à saúde; e 16\% informaram não correrem risco de adquirir patologias ingerindo esses lácteos (Figura 15). De acordo com Ordoñez (2005) essas informações estariam corretas, já que ambos os tratamentos feitos no leite destroem os microrganismos presentes nos mesmos, eliminando os riscos de patologias.

Ainda sobre os entrevistados que informam sobre o leite longa vida e o pasteurizado serem melhores, $10 \%$ responderam acreditar que os mesmos seriam mais práticos, $6 \%$ não souberam responder e $6 \%$ relataram crer que os mesmos têm menos gordura, o que não estaria completamente correto, já que é permitido que esses leites tenham de 3\% de gordura ou mais segundo o Regulamento Técnico de Identidade e Qualidade de Produtos Lácteos, BRASIL (1996). 
A partir da pergunta referente ao que os entrevistados achavam sobre o valor dos leites cru, UHT e pasteurizado, 29\% acreditaram que o leite cru seria mais caro, enquanto $20 \%$ informaram crer que o mesmo seria mais barato; $24 \%$ relataram que o leite UHT seria mais caro, enquanto $11 \%$ responderam que o mesmo seria mais barato; $12 \%$ citaram que o leite pasteurizado seria mais caro, enquanto apenas $4 \%$ informaram que o mesmo seria mais barato, não obtendo-se dados relevantes (Figura 16).

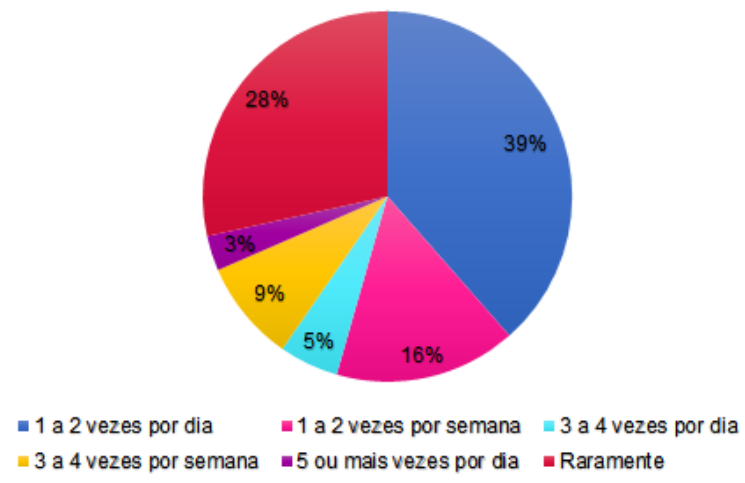

Figura 13. Percentual da frequência de consumo de leite Figura 14. Percentual referente à pergunta feita aos entrevistados UHT ou pasteurizado de acordo com os entrevistados que ingerem o mesmo.

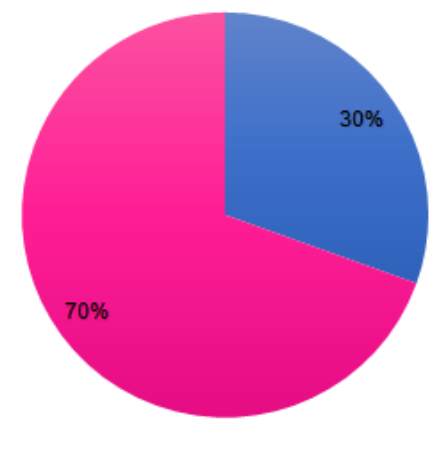

- Sim $=$ Não se os mesmos acreditam que os leites UHT ou pasteurizado seriam melhores que o leite cru.

Em concordância com Pina (2020), os $24 \%$ dos entrevistados estavam corretos ao informar que o leite UHT seria o mais caro, já que a média brasileira de outubro de 2020 de acordo com o CEPEA apresenta o mesmo com o preço de 3,25 reais/litro. O leite mais caro em segundo lugar, sendo representado pelos $12 \%$ dos entrevistados é o leite pasteurizado, concordando com os dados apresentados também por Pina (2020). Em conformidade com os $20 \%$ dos entrevistados, o leite cru é o mais barato de acordo com os dados relatados por Grigol (2020) que informam sobre o preço do mesmo na média brasileira de outubro de 2020 ser de 2,1586 reais/litro.

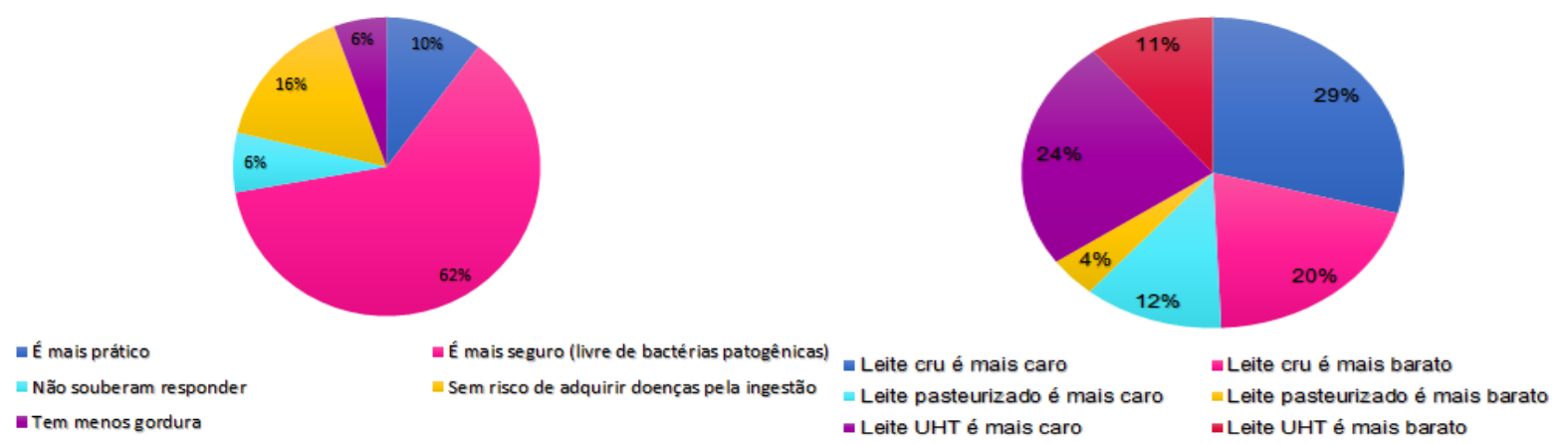

Figura 15. Percentual de respostas dadas pelos entrevistados referentes ao motivo dos mesmos acreditarem que os leites UHT e pasteurizado seriam melhores que o leite cru.

Figura 16. Percentual das respostas dos entrevistados referente à opinião dos mesmos sobre os preços dos leites cru, UHT e pasteurizado.

\section{Conclusão}

Na população estudada, ocorre a ingestão de grande quantidade de leite pasteurizado ou UHT, movimentando boa parte da indústria brasileira. $\mathrm{O}$ seu consumo poderá crescer ainda mais pelo fato de ser uma bebida prática para o consumo por conta de sua embalagem, por possuir alto valor nutricional, e por ser um produto sem riscos de causar patologias pelo seu processamento térmico, ao passo que ainda há preconceitos referentes à esses lácteos por conta de fraudes notificadas em jornais, fazendo a população acreditar que todos os leites possuem aditivos químicos.

\section{Referências}

Abreu, D. D. C., \& Moésia, R. R. (2017). Análise microbiológica do leite bovino não industrializado comercializado na cidade de Cajazeiras, Paraíba. Revista Verde de Agroecologia e Desenvolvimento Sustentável, 12(3), 629-633. https://doi.org/10.18378/rvads.v12i3.4487. 
Amancio, O. M. S. (2015). A importância do consumo de leite no atual cenário nutricional brasileiro. In São Paulo, Sp: Sban (p. 28).

BRASIL. Regulamento da Inspeção Industrial e Sanitária de Produtos de Origem Animal (RIISPOA). Decreto $N^{\circ}$ 9013, de 29 de março de 2017. Regulamenta a Lei ${ }^{\circ} 1283$ de 18 dezembro de 1950, e a Lei 7889, de 23 de novembro de 1989, que dispõem sobre a inspeção industrial e sanitária de produtos de origem animal. Diário Oficial da União: Brasília, Art. 251, p. 71, 2017.

BRASIL. Regulamento da Inspeção Industrial e Sanitária de Produtos de Origem Animal (RIISPOA). Decreto $N^{\circ}$ 9013, de 29 de março de 2017. Regulamenta a Lei ${ }^{\circ} 1283$ de 18 dezembro de 1950, e a Lei 7889, de 23 de novembro de 1989, que dispõem sobre a inspeção industrial e sanitária de produtos de origem animal. Diário Oficial da União: Brasília, Art. 255, p. 72, 2017.

BRASIL. Regulamento da Inspeção Industrial e Sanitária de Produtos de Origem Animal (RIISPOA). Decreto $N^{\circ}$ 9013, de 29 de março de 2017. Regulamenta a Lei no 1283 de 18 dezembro de 1950, e a Lei 7889, de 23 de novembro de 1989, que dispõem sobre a inspeção industrial e sanitária de produtos de origem animal. Diário Oficial da União: Brasília, Art. 256, p. 73, 2017.

BRASIL. Regulamentos Técnicos de Identidade e Qualidade dos Produtos Lácteos (RTIQ). Portaria No 146 de 07 de março de 1996. Aprovado pelo Decreto n ${ }^{\circ}$ 1255, de 25 de junho de 1962, alterado pelo Decreto no 1812 de 08 de fevereiro de 1996. Diário Oficial da União: Brasília, p. 193, 1996.

Greenberg, D. M., Warrier, V., Allison, C., \& Baron-Cohen, S. (2018). Testing the EmpathizingSystemizing theory of sex differences and the Extreme Male Brain theory of autism in half a million people. Proceedings of the National Academy of Sciences, 115(48), 12152-12157. https://doi.org/10.1073/pnas.1811032115.

Grigol, N. (2020). Preço do leite captado em outubro e pago em novembro deve registrar queda (pp. 1-4). Centro de Estudos Avançados em Economia Aplicada.

Lechakoski, R. M., \& Wildauer, E. W. (2013). Os idosos na internet: uma análise da utilização da internet pelos idosos no Brasil. Revista de UniCuritiba, 13(1). https://doi.org/0.21902/RevPercurso.2316-7521.v1i13.663.

Longhi, R., Moreno, A. C. P., Reis, A. B., Okano, W., Aragon-Alegro, L. C., \& Santana, E. H. W. (2010). Perfil dos consumidores de leite cru da cidade de Arapongas-PR. Revista Do Instituto de Laticínios Cândido Tostes, 65(373), 14-19.

Ordoñez, J. A. (2005). Tecnologia de Alimentos: Alimentos de Origem Animal. Artmed Editora.

Pina, D. Z. B. (2020). Lácteos se desvalorizam em outubro (pp. 1-2).

Resende, J. C., Leite, J. L. B., \& Stock, L. A. (2020). Modelo de integração na cadeia produtiva do leite (pp. 87-89). EMBRAPA.

Siqueira, K. B. (2019). O mercado consumidor de leite e derivados. Circular Técnica Embrapa, 120, 117.

Sordi, E., Skonieski, F. R., Castamann, A., \& Zocche, F. (2015). Perfil do consumidor de leite na cidade de Erechim-RS. Revista Brasileira de Tecnologia, 9(2), 1836-1846. https://doi.org/10.3895/rbta.v9n2.1654.

Stock, L. A., Leite, J. L. B., \& Resende, J. C. (2020). Produção mundial de leite: tendências nos principais países (pp. 56-57). EMBRAPA.

Vidal, A. M. C., \& Saran Netto, A. (2018). Obtenção e processamento do leite e derivados. Faculdade de Zootecnia e Engenharia de Alimentos da Universidade de São Paulo.

Histórico do artigo:

Recebido: 20 de janeiro de 2021

Aprovado: 18 de março de 2021
Licenciamento: Este artigo é publicado na modalidade Acesso Aberto sob a licença Creative Commons Atribuição 4.0 (CC-BY 4.0), a qual permite uso irrestrito, distribuição, reprodução em qualquer meio, desde que $\mathrm{o}$ autor e a fonte sejam devidamente creditados. 